XXIV SEMINÁRIO DE INICIAÇÃO CIENTÍFICA DA UEFS

SEMANA NACIONAL DE CIÊNCIA E TECNOLOGIA - 2020

\title{
MANEJO E CONSERVAÇÃO DE SEMENTES CRIOULAS EM COMUNIDADES RURAIS DE AMÉLIA RODRIGUES - BAHIA.
}

\author{
Ravel de Carvalho CONCEIČ̃̃ ${ }^{\mathbf{1}}$; Marina Siqueira de CASTRO²; \\ 1. Bolsista PIBIC/CNPq, Graduando em Agronomia, Universidade Estadual de Feira de Santana, e-mail: \\ ravel.agro@hotmail.com \\ 2. Orientador, DCBio, Cearis, Universidade Estadual de Feira de Santana, e-mail: marinacastro@uefs.br
}

PALAVRAS-CHAVE: agrobiodiversidade; agroecologia; variedades locais.

\section{INTRODUÇÃO}

A presente pesquisa teve como foco principal conhecer as variedades de sementes tradicionalmente cultivadas, ou crioulas, investigando os usos e as práticas de manejo e conservação dessa agrobiodiversidade bem como, discutir o estado da arte sobre sementes crioulas e os serviços ecossistêmicos gerados pela reprodução, conservação e manutenção dessa diversidade

São denominadas sementes crioulas as variedades produzidas por agricultores familiares, quilombolas, indígenas ou assentados da reforma agrária com determinadas características reconhecidas pelas comunidades que as cultivam. Tais sementes são passadas de geração em geração sendo estas de relevante importância econômica e social e ambiental para as comunidades (TRINDADE, 2006).

Santilli (2009) afirma que a agrobiodiversidade, ou a diversidade agrícola, constitui uma parte importante da biodiversidade e engloba todos os elementos que interagem na produção agrícola: os espaços cultivados ou utilizados para a criação de animais domésticos, as espécies direta e indiretamente manejadas, como as cultivadas e seus parentes silvestres, as ervas daninhas, os parasitas, os microrganismos, os polinizadores, os predadores, os simbiontes e a diversidade genética a eles associada também chamada de diversidade intraespecífica.

A conservação da agrobiodiversidade não é apenas uma questão ambiental. A segurança alimentar e nutricional de toda a população, o desenvolvimento rural sustentável, a inclusão social, o combate à fome e a miséria estão, direta ou indiretamente, relacionados à conservação e ao uso dos recursos da agrobiodiversidade. (MACHADO et al., 2008).

A agricultura familiar através de suas especificidades tem sido considerada como potencial aliada do meio ambiente, especialmente no que diz respeito ao uso e preservação dos recursos naturais. Segundo Rodrigues (2012), que evidencia o caráter da pluriatividade nas unidades agrícolas, por tanto, maior diversidade sendo manejada, como favorecimento na geração de serviços ecossistêmicos que influenciam nas questões de produtividade e resiliência diante de agressões abióticas ou surgimento de pragas. 
Neste sentido compreender a realidade das sementes crioulas ou variedades locais nas comunidades pesquisadas nos permite visualizar questões sobre a sustentabilidade das mesmas e das unidades familiares, bem como a busca por literaturas e trabalhos com acúmulos fundamentados seja por experiencias práticas ou debates teóricos, técnicoscientíficos, que possam contribuir com reflexões importantes para contribuir na formulação de estratégias que fortaleçam as práticas de organização, conservação e manutenção da agrobiodiversidade local.

\section{METODOLOGIA}

\section{1 - LEVANTAMENTO BIBLIOGRÁFICO}

O levantamento bibliográfico foi realizado com base no trabalho de ROCHA (2017) que revisou os conhecimentos do estado da arte sobre os benefícios ecossistêmicos na conservação das variedades tradicionalmente cultivadas com publicações de 2007 a 2017. Demos continuidade a metodologia utilizada pela autora buscando complementar as discussões em torno do tema através de artigos publicados entre os anos seguintes de 2017 até o presente ano de 2020.

Utilizou-se a plataforma do portal da Coordenação de Aperfeiçoamento de Pessoa de Nível Superior (CAPES) (www.periodicos.capes.gov.br), do site de buscas de publicações Scielo (www.scielo.org/php/index.php) e a plataforma do Google Acadêmico em busca de artigos entre outras publicações que abordam os temas desta pesquisa. As palavras chave utilizadas e as combinações feitas na busca dentro das plataformas foram as mesmas utilizadas por ROCHA (2017) seguido de palavras chave que trouxessem as contribuições socioeconômicas e culturais.

\section{2 - PESQUISA COM AGRICULTURES}

As comunidades que fizeram parte da pesquisa foram: Fazenda Campos, a comunidade remanescente de quilombo da Pinguela e a comunidade Quatro Estradas. As três comunidades possuem características sociais, culturais, econômicas e de produção bem diferenciadas.

O modelo metodológico na pesquisa se deu através da aplicação de questionário, aberto, semiestruturado através de um modelo já trabalhado pelo Núcleo de Estudos em Agroecologia - NEA/Trilhas, desenvolvido durante os oito anos de pesquisa com estas comunidades rurais.

As entrevistas partiram dos informantes-chave identificados nas comunidades que segundo Bernard \& Ryan (2010) são pessoas que são reconhecidas pelo grupo em que vivem como detentores de conhecimento e através dos mesmos utilizamos o método de "bola de neve" no qual, Goodman (1961) nos diz que um indivíduo especialista no tema é recrutado e, em seguida, indica outras pessoas de seu relacionamento para que também participem da amostra.

\section{RESULTADOS E DISCUSSÃO}

\section{1 - O ESTADO DA ARTE SOBRE SEMENTES CRIOULAS}


Na revisão bibliográfica complementando os temas levantados por Rocha (2017), foram encontrados 56 registros bibliográficos, desse total 26 trabalhos foram selecionados e fichados. Rocha (2017) fichou 40 trabalhos e nomeou 6 temas reunindo os conhecimentos ecológicos identificados, o que em nossos resultados pudemos reunir em 8 categorias distintas (tabela 1), duas a mais com uma publicação pra cada, com tema referente a Gênero e conservação de sementes crioulas e outra sobre a importância das entidades de base para as estratégias de conservação da agrobiodiversidade.

Tabela 1. Conhecimentos ecológicos identificados.

\begin{tabular}{|c|c|}
\hline CATEGORIAS & $\begin{array}{c}\mathbf{N}^{\circ} \text { Artigos selecionados } \\
\text { Total (40) Total (26) } \\
2007-2017-2020 \\
\text { (Rocha, 2017) (este estudo) }\end{array}$ \\
\hline $\begin{array}{l}1 \text { - Variedades locais e relações com a } \\
\text { agricultura familiar }\end{array}$ & $9 \quad 17$ \\
\hline $\begin{array}{l}2 \text { - Relação entre a perda da biodiversidade nos } \\
\text { seus diversos níveis com a agricultura atual }\end{array}$ & 35 \\
\hline $\begin{array}{l}3 \text { - Variedades locais e serviços } \\
\text { ecossistêmicos associados }\end{array}$ & 8 \\
\hline $\begin{array}{l}4 \text { - Erosão genética de variedades locais e } \\
\text { estratégias para seu uso e conservação }\end{array}$ & 16 \\
\hline 5 - Politica e leis da biodiversidade & 20 \\
\hline $\begin{array}{l}6 \text { - A construção dos saberes em relação a } \\
\text { agrobiodiversidade }\end{array}$ & 22 \\
\hline $\begin{array}{l}7 \text { - Gênero, agroecologia e conservação das } \\
\text { sementes crioulas }\end{array}$ & Não incluído \\
\hline $\begin{array}{l}8 \text { - Entidades de classe e conservação } \\
\text { da agrobiodiversidade }\end{array}$ & Não incluído \\
\hline
\end{tabular}

Fonte: próprio autor (modificado de Rocha, 2017)

Complementando a revisão feita por Rocha (2017) nos temas de 1 a 6 (tabela 1), foram encontradas 17 publicações que evidenciam a importância das iniciativas que tratam da conservação da agrobiodiversidade, tanto no ambiente agrícola como nos espaços de construção de políticas e leis, orientados por princípios que favoreçam a manutenção das variedades crioulas, evidenciando os serviços ecossistêmicos obtidos através da reprodução dessa diversidade que favorece a sustentabilidade econômica, social e cultural das populações agrícolas, sendo seus agroecossistemas o resultado das interações harmoniosas com a natureza numa relação de interdependência, possibilitando a construção dos conhecimentos tradicionais responsáveis pela existência da agrobiodiversidade.

Para os temas 7 e 8 que não foram abordados na revisão de Rocha (2017) pudemos encontrar 2 trabalhos que trouxeram importantes considerações, um sobre a importância da valorização dos trabalhos desenvolvidos por mulheres como grandes responsáveis na prática familiar e comunitária da salvaguarda dessa diversidade, essas mulheres são denominadas guardiãs das sementes crioulas.

O outro trabalho discute sobre a importância das entidades de organização civil (associações, sindicatos, entre outros) na construção de estratégias para a conservação da agrobiodiversidade, aproximando os guardiões e as guardiãs, podendo facilitar ações em conjunto o que inclui, segundo Silva (2019), o incentivo à conservação, multiplicando e partilhando as sementes dentro das comunidade, além de fortalecerem a participação ativa dos agricultores familiares para tomada de decisões referentes ao Território. 


\section{2 - AS SEMENTES DAS COMUNIDADES}

Para a comunidade Quatro Estradas foi possível observar que nos dias de hoje, as áreas já são muito menores do que um módulo considerado para uma agricultura familiar na região de Amélia Rodrigues. Seu retrato demonstra uma comunidade com suas áreas reduzidas devido a existência de uma fazenda de gado considerada como latifundiária, nos fundos da mesma, e as unidades possuem características de quintais. Neste sentido não houveram condições de executar um estudo mais aprofundado com relação as sementes crioulas, já que os mesmos produzem fruteiras advindas de enxertias, pequenas hortas, plantas medicinais e criam galinhas. Perdendo assim a prática de guardar as sementes. Nesse sentido a pesquisa foi aprofundada nas comunidades Fazenda Campos e Pinguela.

Na tabela 2 podemos observar as principais espécies cultivadas por comunidade, o que nos permite perceber que há pouca variação de espécies entre uma comunidade e outra, refletindo um princípio que defina a oferta e a escolha do cultivo de espécies, baseado na demanda de procura nas feiras onde seus produtos são comercializados.

Tabela 2. Lista de Espécies Cultivadas por Comunidade estudada

\begin{tabular}{|c|c|c|}
\hline $\begin{array}{c}\text { LISTA DE ESPÉCIES } \\
\text { CULTIVADAS }- \\
\text { PINGUELA }\end{array}$ & NOME CIENTÍFICO & $\begin{array}{c}\text { LISTA DE ESPÉCIES } \\
\text { CULTIVADAS - FAZENDA } \\
\text { CAMPOS }\end{array}$ \\
\hline MILHO & Zea mays & MILHO \\
\hline AMENDOIM & Vigna unguiculata & FEIJÃO DE CORDA \\
\hline FEIJÃO DE ARANQUE & Phaseolus vulgaris & AMENDOIM \\
\hline ABÓBORA & Cucurbita moschata & ABÓBORA \\
\hline QUIABO & Abelmoschus esculentus & QUIABO \\
\hline ABOBRINHA & Cucurbita pepo & COENTRO \\
\hline & Coriandrum sativum & MELANCIA \\
\cline { 2 - 3 } & Citrullus lanatus & MANGALÔ \\
\hline GIRIMUM & Curcubita Maxima & ANDÚ \\
\hline & Lablab purpureus & MANDIOCA \\
\cline { 2 - 3 } & Cajanus Cajan (L. Millsp.) & \\
\hline MANDIOCA & Manihot esculenta & \\
\hline
\end{tabular}

Fonte: Elaborado pelo autor

A figura 1 apresenta as principais espécies de interesse econômico cultivadas entre os entrevistados/das, onde é possível observar a predominante opção pelo monocultivo dessas espécies, resquício das práticas de cultivo oriundas da modernização agrícola sendo introduzida sobretudo pelas políticas de abastecimento de sementes geneticamente uniformes e seus pacotes tecnológicos em toda região. 


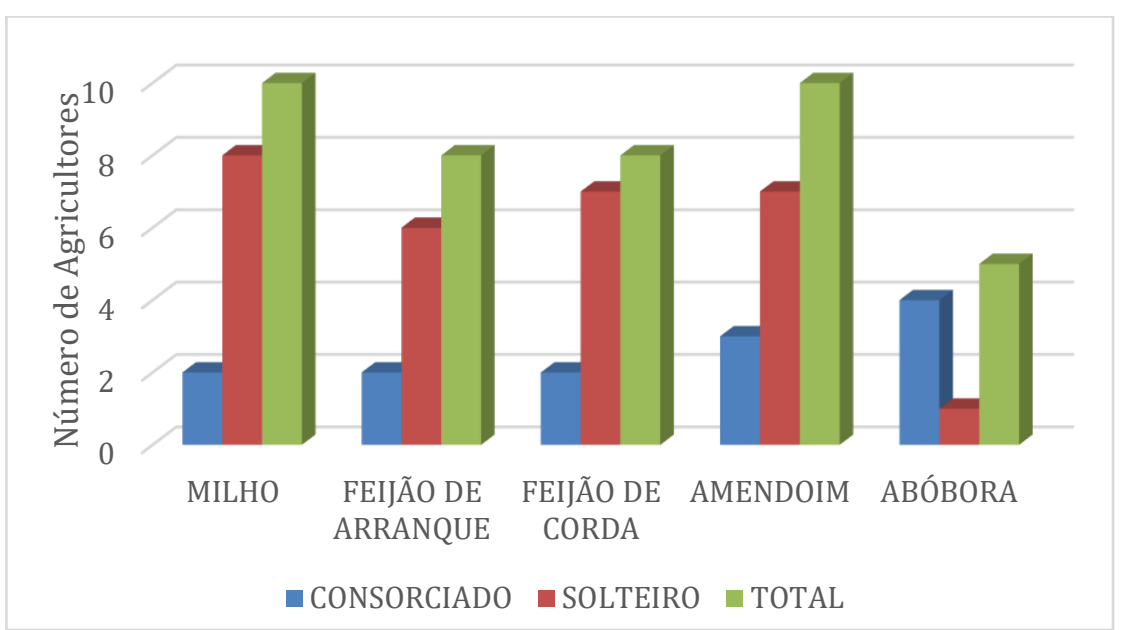

Figura 1: Cultivo Consorciado/ Solteiro das principais espécies produzidas.

Sobre as variedades das espécies cultivadas, é possível perceber o processo de erosão genética principalmente para o cultivo de Feijão de Arranque (Phaseolus vulgaris), mostrando a diminuição de suas variedades a partir da memória dos agricultores, além da diminuição ou inexistência na quantidade de mais espécies e de variedades adaptadas e desenvolvidas da maioria dos cultivos de espécie citadas (tabela $3)$.

Tabela 3 - Lista de variedades por espécies cultivadas

\begin{tabular}{|c|c|c|c|c|c|c|c|}
\hline ESPÉCIIS & \multicolumn{7}{|c|}{ VARIE DADES } \\
\hline $\begin{array}{l}\text { FEUÃO DE } \\
\text { ARRANQUE }\end{array}$ & Enxofre & Grosso & Xita Fina & Mula tinho & Leite & Preto & Canioca \\
\hline FEUÃO DE CORDA & Corujinha & Costela de Vaca & & & & & \\
\hline MILHO AMENDOIM & Papuco roxo & Muleque/Batim & Crioulo & & & & \\
\hline AMENDOIM & Maranhão & Miúdo & Vermetho & & & & \\
\hline QUIABO & Sana Cruz & & & & & & \\
\hline \multicolumn{8}{|l|}{ MELANCIA } \\
\hline \multicolumn{8}{|l|}{ MANGALÔ } \\
\hline \multicolumn{8}{|l|}{ ANDÚ } \\
\hline \multicolumn{8}{|l|}{ COENTRO } \\
\hline \multirow{2}{*}{\multicolumn{8}{|c|}{$\begin{array}{c}\text { ABOBRINHA } \\
\text { GIRIMUM }\end{array}$}} \\
\hline & & & & & & & \\
\hline \multicolumn{8}{|c|}{ Variedades ainda cultivadas } \\
\hline \multicolumn{8}{|c|}{ Variedades não mais cultivadas } \\
\hline Variedades & io encont & & & & & & \\
\hline
\end{tabular}

Sobre as formas de obtenção das sementes cultivadas nas comunidade, pudemos observar que existe uma preocupação maior em conservar a posse das variedades de maior interesse econômico pelos agricultores, pois garante o plantio para as proximas épocas.

Para as formas de estocagem das sementes produzidas nas comunidades, o uso de garrafas PET é quase que totalitário entre os agricultores na conservação das sementes e suas variedades. A conservação em garrafas PET apresenta vantagens como relata Souza (2010), na conservação da germinação das sementes, proporcionando uma grande resistência a trocas gasosas somado a característica semipermeável, favorecendo a difícil absorção de umidade do meio externo.

Os entrevistados citaram algumas formas de tratamento para o aumento na conservação de suas sementes contra carunchos e umidade. Para algumas culturas, principalmente para as espécies de leguminosas e ou Milho (Zea mays), os agricultores 
relataram como melhor tratamento o acondicionamento das sementes na própria vagem ou paiol em lugares secos, sombreados e sem umidade.

Questionados sobre seus conhecimentos em relação as sementes transgênicas a maioria dos entrevistados correlacionaram o que sabem com o uso de agrotóxicos e a inviabilidade de reprodução das gerações seguintes devido a condição de esterilidades dessas sementes, não sendo condicionadas e serem sempre compradas para obter as devidas colheitas.

Sob o reconhecimento da importância das sementes crioulas para a agricultura familiar, os entrevistados foram indagados sobre de que forma, caso positivo, atuariam em trabalhos relacionados ao resgate e conservação das sementes crioulas nas comunidades, em quase sua totalidade todos responderam atuando como guardiões e estimulando a participação dos outros agricultores da comunidade a participarem das iniciativas. Segundo Bevilaqua (2014) os guardiões desenvolvem técnicas empíricas de cunho sociocultural para resgate, manutenção e dispersão dos materiais crioulos, cujas práticas são passadas de geração em geração. No entanto, não foi constatada a participação das mulheres como efetivas guardiãs das sementes das comunidades como demonstrado para outras localidades, cujas referências foram localizadas na revisão da literatura desta pesquisa.

\section{CONSIDERAÇÕES FINAIS}

Podemos considerar que nas comunidades pesquisadas houve um processo de erosão genética em relação as espécies tradicionalmente cultivadas, bem como a diminuição das variedades das espécies que restaram nos cultivos, havendo a diminuição da agrobiodiversidade crioula. Esse processo demonstra-se continuo, podendo avançar de forma intensiva caso não haja trabalhos voltados para a conservação dessas espécies e suas variedades onde questões sociais e econômicas influenciam diretamente sobre essa dinâmica dentro e fora das unidades familiares, como por exemplo a não permanência dos jovens no campo e o fim dos canais hereditários de transmissão do conhecimento sobre as espécies, os sistemas de cultivo e a adoção de práticas de manejo que sejam contrários ao manejo sustentável da diversidade bem como a criação de formas de valorização econômica dos produtos dessa agrobiodiversidade, gerando renda e contribuindo para o arrefecimento dos conflitos causados pela diminuição da agrobiodiversidade para as comunidades tradicionais da agricultura familiar ou não.

\section{REFERÊNCIAS}

BERNARD, H. R. \& RYAN, G. W. Analyzing Qualitative Data: Systematic Approaches. Sage Publication. 2010.

BEVILAQUA, G. A. P. ANTUNES, I. F. BARBIERI, R. L. SCHWENGBER, J. E. SILVA, S. D. A. LEITE, D. L. CARDOSO, J. H. Agricultores guardiões de sementes e ampliação da agrobiodiversidade. Cadernos de Ciência \& Tecnologia, Brasília, v. 31, n. 1, p. 99-118, jan./abr. 2014.

GOODMAN, L. Snowball sampling. Annals of Mathematical Statistics, 32: 148-170. 1961. 
MACHADO, A. T. SANTILli, J. MAGAlHÃES, R. A Agrobiodiversidade com enfoque Agroecológico: implicações conceituais e jurídicas. Embrapa Informações Tecnológicas, 2008. Brasília, DF. 98p.

ROCHA, E, A. Conhecimento ecológico associado ao uso e conservação das sementes tradicionais ou crioulas e variedades locais. MSc diss. Salvador, 2017. 133 p. 2017.

RODRIGUES, J. A. FIGUEIREDO, R. B. TI Verde - Sustentabilidade. Centro Universitário Newton Paiva, Belo Horizonte, MG, 2012. Disponível em: <http://pt.scribd.com/doc/92637411/TI-Verde-Artigo2>. Acesso em: 26 de agosto de 2020.

SANTILLI, Juliana Ferraz Rocha. Agrobiodiversidade e direito dos agricultores. Tese. Programa de Pós-graduação em Direito. Pontifícia Universidade Católica (PUC). Curitiba, 2009.

SILVA, D. P. SANT'ANA, A. L. Identificação e caracterização dos guardiões de sementes crioulas dos Assentamentos rurais do Território Prof. Cory/Andradina - SP. Revista Retratos de Assentamentos, Vol. 22 N.2, Andradina - SP, 2019.

SOUZA, G. J. Armazenamento artesanal de sementes de milho crioulo na propriedade. TCC. Especialização em Educação do Campo da Universidade Federal do Paraná. Matinhos - PR, 2011.

TRINDADE, C, C. Sementes crioulas e transgênicos, uma reflexão sobre sua relação com as comunidades tradicionais. Universidade do Estado do Amazonas. 2006. Disponível em: $<$ http://www.conpedi.org.br/manaus/arquivos/anais/manaus/estado_dir_povos_carin a_carreira_trindade.pdf $>$ Acesso em 20 de agosto de 2020 . 